CASE 2. Sergeant H.L.G., aged 28, years.-Had always had good vision until twelve years previously, when he was struck a violent blow in the left eye. After that he could never see well with that eye, and reading vision never returned. On examination the vision in this eye was less than $6 / 60$, and the macula showed pigmentary changes such as one would expect to find after the subsidence of traumatic oedema (Fig. 2).

CASE 3. J.S., aged 29 years, a soldier.-Four years previously he had had a severe motor-bike accident and was unconscious for four days. The damage was chiefly to the right side of the head, and there was a large scar over the right eyebrow. After the accident his $R$. vision failed and he found he could not shoot from the right shoulder. On this account he was transferred to the Ordnance Corps.

On examination the vision of the right eye was finger counting at 2 feet, no improvement with lenses. There was a punched out hole at the right macula, and the surrounding retina was slightly detàched (Fig. 3).

CASE 4. J.S., schoolboy, aged 9 years.-Three years previously he was struck on the left upper lid by an air-gun pellet. After this he could not see well with this eye, and has never done so since.

Examination L. eye, less than $6 / 60$, not improved. There was a circular punched out hole over the left macula; and a thin disc of tissue floating in the vitreous in front of it. The inferior half of the retina was detached. No other retinal hole found (Fig. 4).

My thanks are due to Mr. J. E. A. O'Connell for asking me to see cases 1 and 3 while they were under his care at Hill End Hospital.

\title{
A CASE OF FISTULA OF THE CORNEA. A METHOD OF TREATMENT
}

BY

\author{
J. B. MCAREVEY \\ - dUBLIN
}

DE SCHwEINITZ defines a fistula of the cornea as an orifice remaining after a wound, or more commonly because of the failure of an ulcer to heal. Fistula is an unusual sequel and when it does occur it is the central part of the cornea that is most often affected. De Schweinitz recommends to touch the mouth of the fistula with the point of the lunar caustic-and even to pare the edges and introduce a corneal suture. In Fuchs' Text-Book of Ophthalmology the line of treatment suggested is :- 


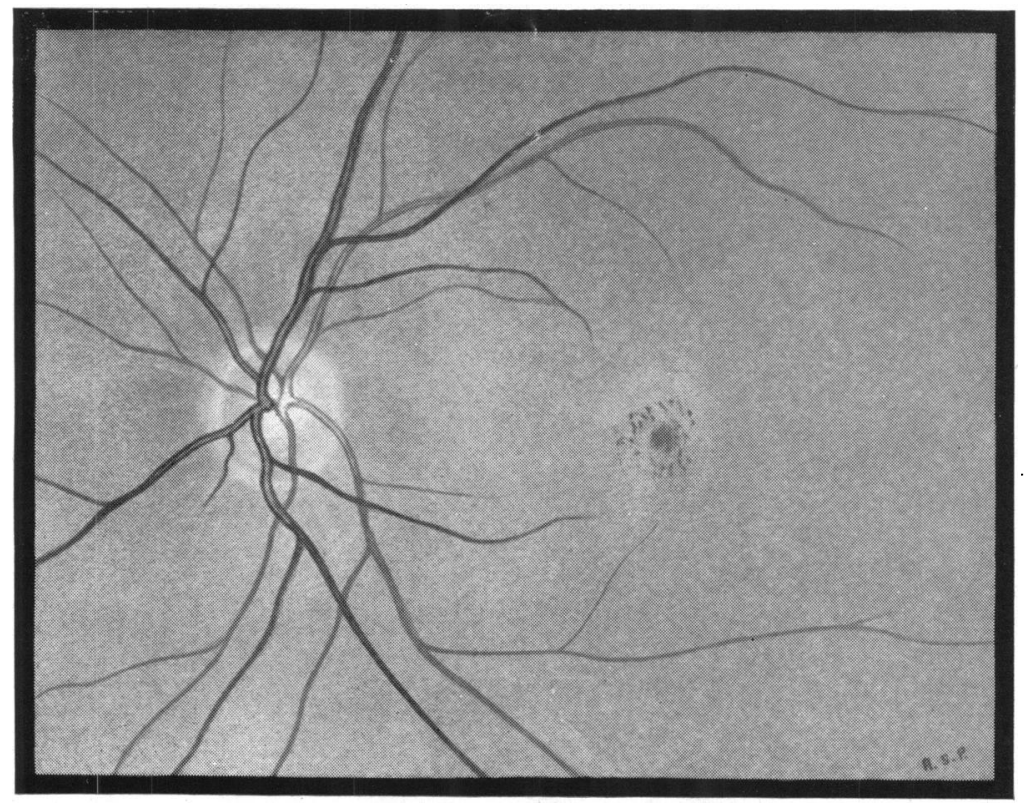

Fig. 1.

The left eye of E. L. after. a wall had collapsed on him. Traumatic oedema of the macula.

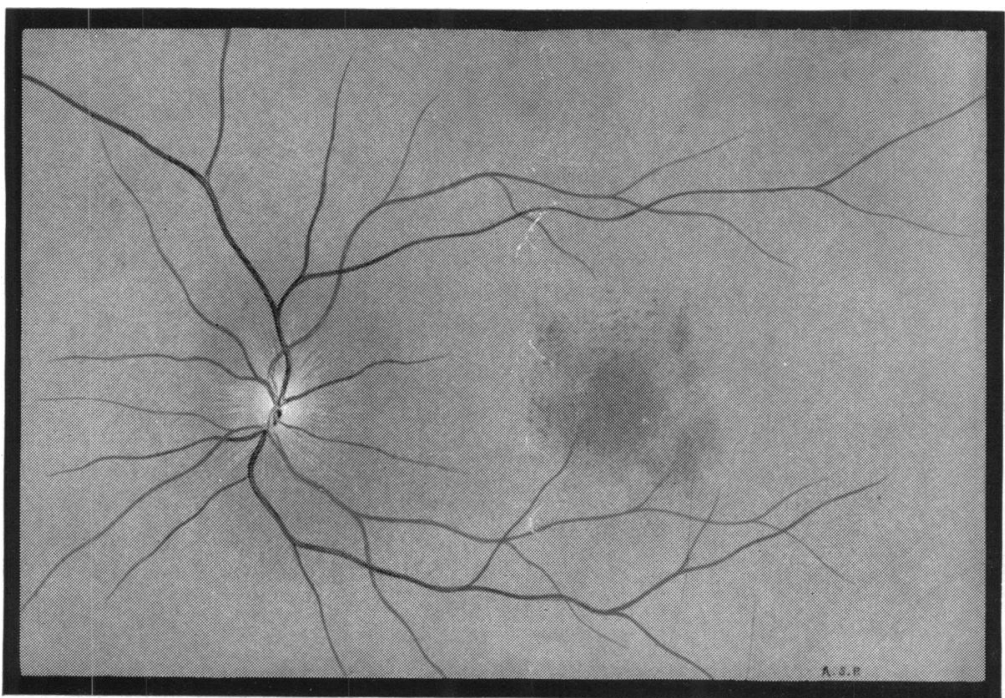

Fig. 2.

Sergeant H. L. G. Pigmentary changes at the left macula probably following traumatic oedema. 
Fig. 3.

The right eye of $\mathrm{J}$. S. four years after a severe head injury. Hole at the macula.

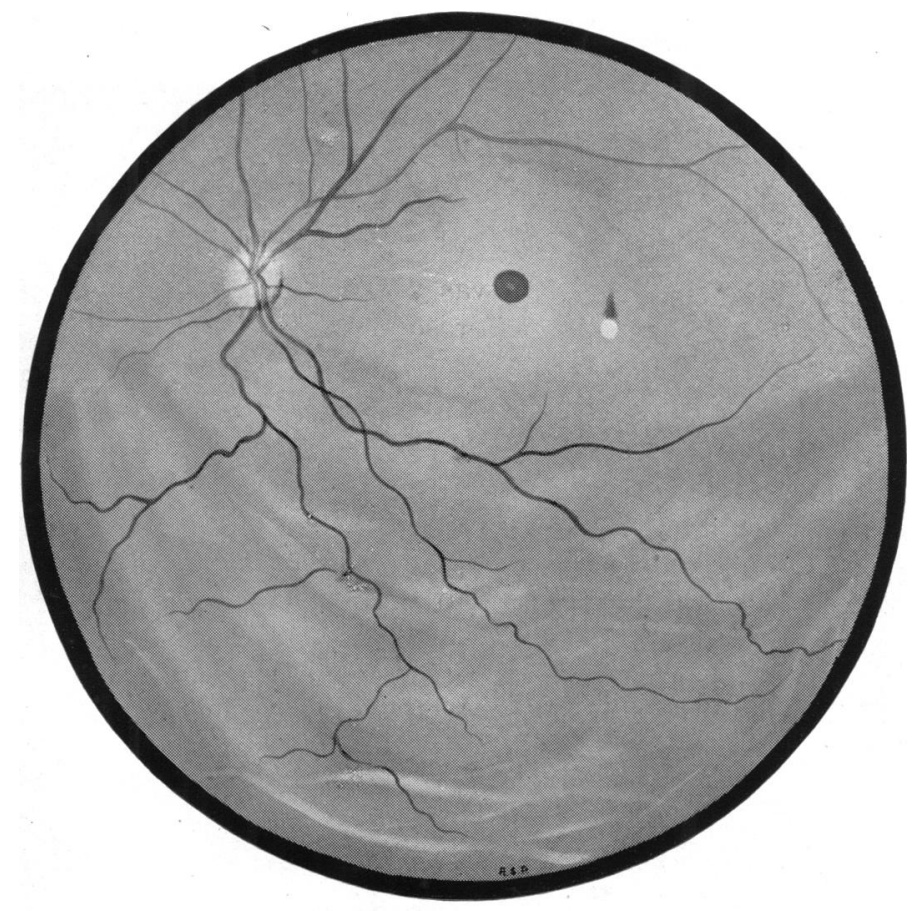

FIG. 4.

The left eye of J. W. three years after he had been struck in the left lid by an air-gun pellet. Macular hole with retinal detachment. 
1. To avoid everything that might temporarily increase the ocular tension.

2. The use of miotics and a light pressure bandage.

3. If closure does not succeed a cauterization of the edges of the wound (this pre-supposes the presence of an anterior chamber on account of injury to the lens), again failing closure the use of a conjunctival flap having removed the epithelium, and as a last resort the removal of cicatricial tissue and implanting in the opening a piece of healthy cornea.

The presence of an anterior chamber has a bearing on the treatment; in the case I am reporting there was a definite hole through the cornea which appeared to have a uniform diameter of about a millimetre. To close the hole either a conjunctival flap or a graft would be necessary, the treatment with light pressure bandages for over a week having proved ineffective.

It occurred to me that as there was such a slight loss of tissue the swelling of the corneal stroma might close the hole and allow cicatrization to take place if the sides of the fistula were freshened up.

A man aged 27 years was working with metal and a piece flew off and hit him in the right eye, This patient was referred to me five days after the accident. Examination showed left eye normal. Right eye relatively quiet with slight watering, no anterior chamber present, contracted pupil, small central opacity of the cornea $2 \mathrm{~mm}$. in size, mydricaine dilated the pupil well; $\mathrm{X}$-ray negative, magnet negative, vision $3 / 60$, fundus appeared normal, slit-lamp examination showed in centre of the opacity a hole in the cornea which appeared to have a uniform diameter of about $1 \mathrm{~mm}$., from the end of the fistula on posterior surface of the cornea Descemet's membrane radiated in folds. There was no anterior chamber and the lens was normal. On putting fluorescein into the conjunctival sac and washing away any excess, green circles started from the mouth of the fistula increasing in size as they passed towards the periphery of the cornea; fluorescein should be used as a diagnostic aid in doubtful leaking corneal wounds.

Under a local anaesthetic a series of perforations were made into the clear cornea just outside the opacity with a discission needle, these perforations were intended to enter the fistula at different levels, in addition three small incisions were made into the corneal stroma with a Ziegler knife-a fine probe was passed into these openings and pushed the corneal tissue towards the fistula. Both eyes were occluded with a light pressure bandage. In 48 hours the bandage was removed. The anterior chamber had reformed. The injured eye was kept bandaged for 5 days longer. After a week the patient was discharged from hospital. 
Slit-lamp examination before leaving hospital showed what appeared to be a healed corneal wound with still some folding (greatly reduced) of Dešcemet's membrane, a normal anterior chamber, the eye free from inflammation, vision $6 / 18$ and no apparent increase in the size of the original corneal opacity.

Summary.-A case of fistula or hole in the cornea is reported. Fluorescein is suggested as a confirmatory test in leaking corneal wounds and a method of treatment is described.

\title{
REFERENCES
}

1. DE SCHWEINIT2.-Diseases of the Eye, 10th Edition, p. 288.

2. Fuchs' Text-Book of Ophthalmology, 6th Edition (Duane), p. 265.

\section{AN OPERATION FOR ENTROPION OF TRACHOMA}

\author{
BY \\ MAJOR C. COCKBURN, R.A.M.C:
}

IT is to be noted that the operation described below is essentially a slight modification of that described by Busacca. (Arch. Ophthal., November 16, 1936).

As eye specialist to a Libyan prisoner-of-war camp during 1942, considerable experience in the treatment of trichiasis entropion has been gained, and it is considered justifiable to report on an operation which has been found to be most satisfactory.

About 60 cases, all Libyans, have been operated on. In all instances the disease had reached a chronic fibrotic stage with deformity of the upper tarsal plate and widespread trichiasis.

Anaesthesia.-Nerve block of supra-orbital and frontal nerves and local infiltration of eyelid with novotux and adrenalin.

A Desmarres' entropion forceps is carefully applied to the eyelid and the screw made firm to ensure adequate haemostasis. The skin is incised parallel to the lid margin and about $5 \mathrm{~mm}$. above it. On either side the skin is well undermined to expose the fibres of the orbicularis muscle. The lower lip is freed right down to the cilia. The muscle fibres are then excised exposing the white tarsal plate. It is wise to remove all fibro-fatty tissue from the surface of the plate to facilitate further procedures. A linear incision is then made in the tarsus close to and parallel to its lower margin, down to but not incising the conjunctiva. A similar linear incision is made about $2 \mathrm{~mm}$. above, and a strip of tarsal plate can then be readily excised. Even where the tarsal plate is thin, this procedure 